\title{
PUNCHING SHEAR LOAD TEST MONITORED BY PHOTOGRAMMETRY
}

\author{
L. Fillo*, T. Augustín ${ }^{* *}$, J. Halvonik ${ }^{* * *}$, M. Marčiš ${ }^{\dagger}$
}

\begin{abstract}
The use of photogrammetry during load tests of flat slabs is a common practice all over the world because of its effectiveness, contactless approach, 3D measurement and partial or full automation of image processing. It is possible to achieve an accuracy of $0.03 \mathrm{~mm}$ for all the points measured on the object observed if the camera is close enough to the object, and the positions of the camera and the number of shots are precisely planned. The DSLR camera used during the photogrammetric measurement of the deformations of flat slabs in this contribution was placed on a special hanging frame to achieve optimal camera positions relatively to the object of measurement. The results of the photogrammetric measurements were compared to the results from traditional contact measurement techniques.
\end{abstract}

Keywords: punching resistance, flat slab, openings, photogrammetry, strain

\section{Introduction}

Load test experiments of flat slabs are mostly monitored using traditional linear variable differential transformers (LVDT), strain gauges and deformeters. Although this equipment delivers a high degree of accuracy of the changes in length measured, it is also very limiting as it offers only 1D measurements between points and thus might not be effective in measuring larger objects in sufficient detail. Digital photogrammetry can handle all of these aspects, including the high density of measurements and a high degree of accuracy of the 3D coordinates of the points observed. However, to obtain results that require a high degree of precision, it is very important to implement the proper combination of a camera system, network configuration and processing software with its overall settings. With the use of circular targets, the accuracy measurements of image coordinates in tenths and hundredths of a pixel can be achieved (Luhmann et al., 2006) which can be translated into high degree of accuracy.

The state-of-the-art of industrial photogrammetry is well described by Luhmann (2010), but there were many studies performed in the last 10 years confirming the high achievable accuracy and effectivity of photogrammetry in structural monitoring applications. Interesting results were presented e. g. by Lee et al. (2008), Detchev et al. (2011), Chounta and Ioannidis (2012) or Valença et al. (2012).

\section{Experimental work}

The analyzed specimens were octagonal shaped slabs of a $250 \mathrm{~mm}$ thickness. Two of eight tested specimens were without openings (S0-1, S0-2) and other specimens were with symmetrically placed openings (S1-1, S1-2 - next to column, S2-1, S2-2 - in distance of $d$ from column, S3-1, S3-2 - in

Prof. Ing. Ludovít Fillo, PhD.: Faculty of Civil Engineering, STU in Bratislava, Radlinského 11; 810 05, Bratislava; SK, ludovit.fillo@stuba.sk

** Ing. Tomáš Augustín: Faculty of Civil Engineering, STU in Bratislava, Radlinského 11; 810 05, Bratislava; SK, tomas.augustin@stuba.sk

*** Prof. Ing. Jaroslav Halvonik, PhD.: Faculty of Civil Engineering, STU in Bratislava, Radlinského 11; 810 05, Bratislava; SK, jaroslav.halvonik@stuba.sk

† Ing. Marián Marčiš, PhD.: Faculty of Civil Engineering, STU in Bratislava, Radlinského 11; 810 05, Bratislava; SK, marian.marcis@stuba.sk 
distance of $2 d$ from column (Fig. 1)). The symmetrical positioning of the openings was intentionally chosen to prevent influence of the unbalanced bending moment.

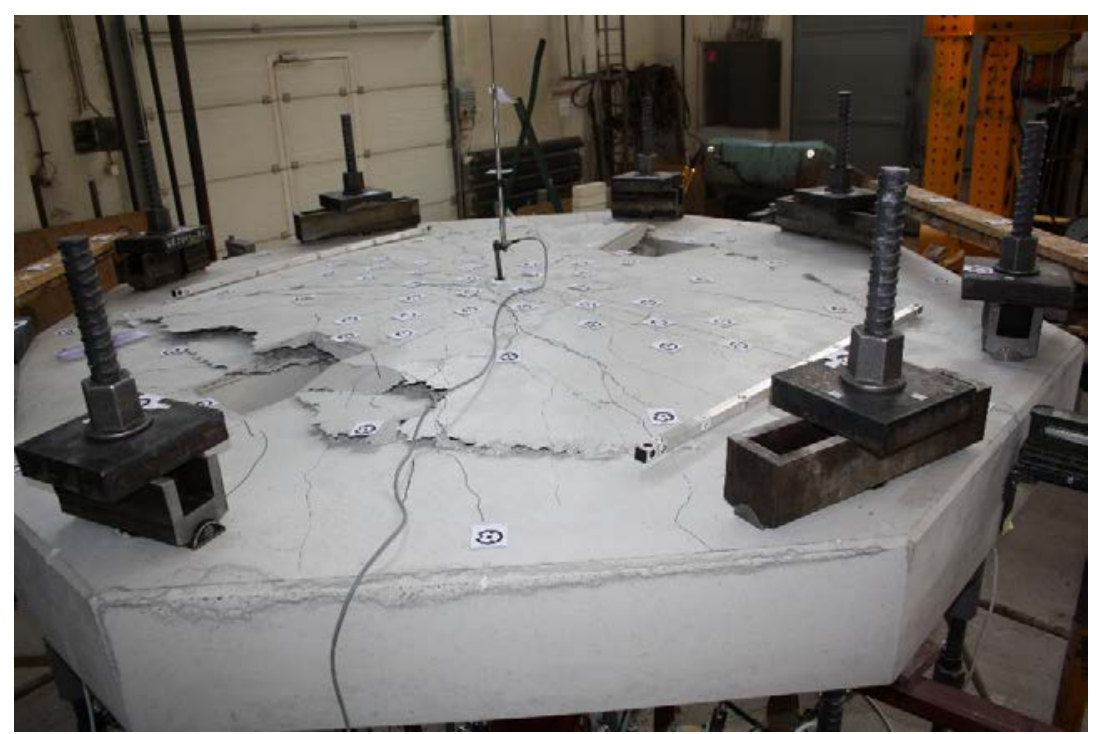

Fig. 1: Damaged specimen with opening of $2 d$ from support

The reinforcement of all slabs was $\Phi 20 / 100 \mathrm{~mm}$ and the 1Ф20 bar was added to each side of the opening in the S1-1 and S1-2 slabs. The strength of the concrete was experimentally determined at the time of each slab test.

The samples were hinged on the top and fixed to the floor of the laboratory using Freyssinet prestressing bars which created a reaction. The sample was loaded under axis-symmetric conditions with a hydraulic jack placed under the slab column $200 \times 200 \mathrm{~mm}$ (Fig. 2 left).

A special hanging frame from Dural was designed to achieve optimal camera positions relatively to the measured slab (Fig. 2 right). The construction enables rotating the arm with a mounted camera around the object and take a theoretically unlimited number of images with ideal angles of the rays' intersection at the photogrammetric points $\left(60^{\circ}\right.$ to $\left.90^{\circ}\right)$. It was designed in such a way that it can be easily modifiable for various camera heights and rotation radiuses. The stability of the mounted camera is gained by a 5-kg counterweight on the opposite side of the arm.
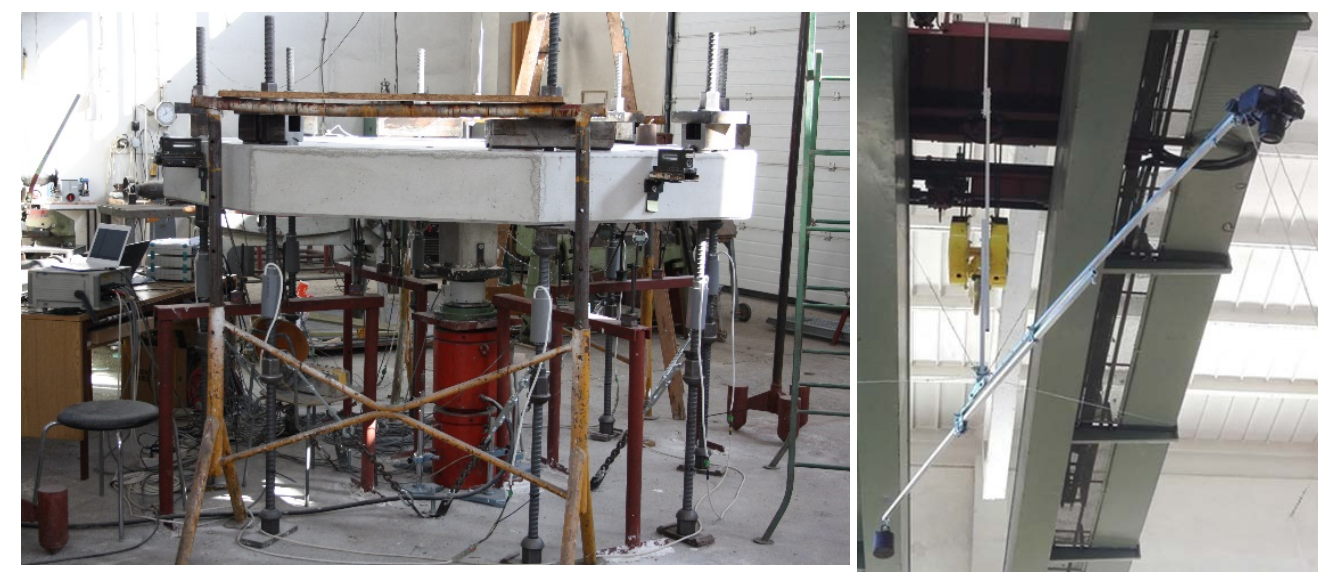

Fig. 2: Experimental set-up photo (left), hanging frame with camera over the slab (right).

\section{Measurement}

The images for photogrammetric processing were taken remotely using a Nikon D800E DSLR equipped by a Nikkon $35 \mathrm{~mm}$ AF-S ED 1:1.8G lens. The average camera-to-object distance was $3 \mathrm{~m} .18$ images were taken at every load stage with a configuration that created a full circle around the specimen (Fig. 3 right). The points observed were signalized by Ringed Automatically Detected Coded targets (RAD) used by PhotoModeler software (Fig. 3 left). 


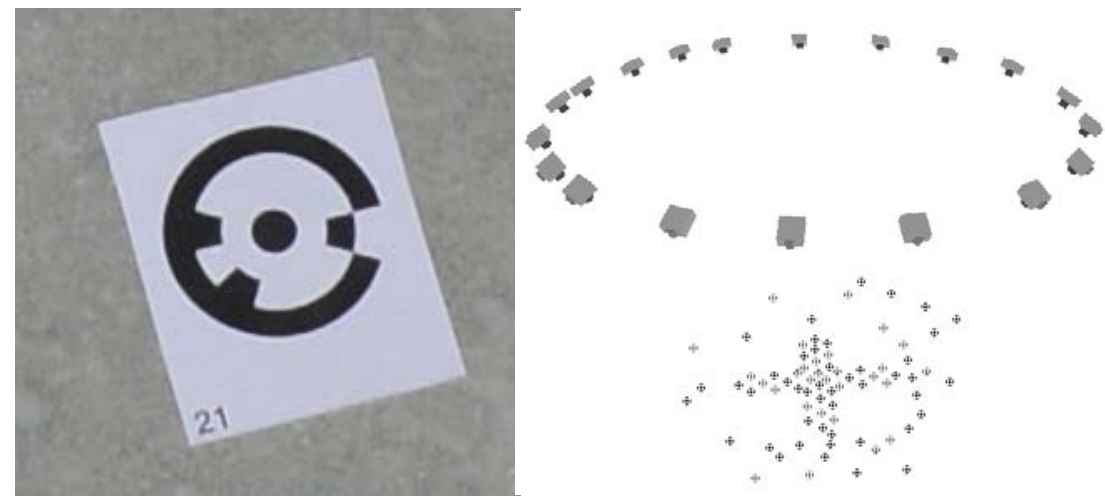

Fig. 3: RAD-targets (left) and camera positions relatively to the photogrammetric points observed (right).

The distribution of points over the specimens' surface was determined by the need for computation of strain in the main reinforcement directions (radial and tangential); thus the overall layout led to a crossshaped structure with $200 \mathrm{~mm}$ spacing. These photogrammetric targets were glued on the specimens' surfaces close to special metal markers used for traditional contact measurement by a deformeter with an accuracy of $0.01 \mathrm{~mm}$. This enabled the comparison of the results from the photogrammetric and deformeter measurements.

The model's scale was determined by two special 1-m-long Dural scale bars with coded targets. The object's coordinate system was defined using 8 targets and stabilized in two perpendicular directions on steel frames around the specimen. This points were considered stable during the load test; however, verification of their stability was done in the processing. A total of 80 targets were placed on the observed object.

\section{Processing and results}

The photogrammetric processing was performed using PhotoModeler software. On-the-job camera calibration was done on the object points, which led to maximum residuals under 0.2 pixel and secured high degree of accuracy in reference coordinate system, reaching $0.03 \mathrm{~mm}$. This was experimentally verified by comparing the strains gained from photogrammetric and from deformeter measurement. An example of comparison between the strains obtained from the two methods is shown in Fig. 4.

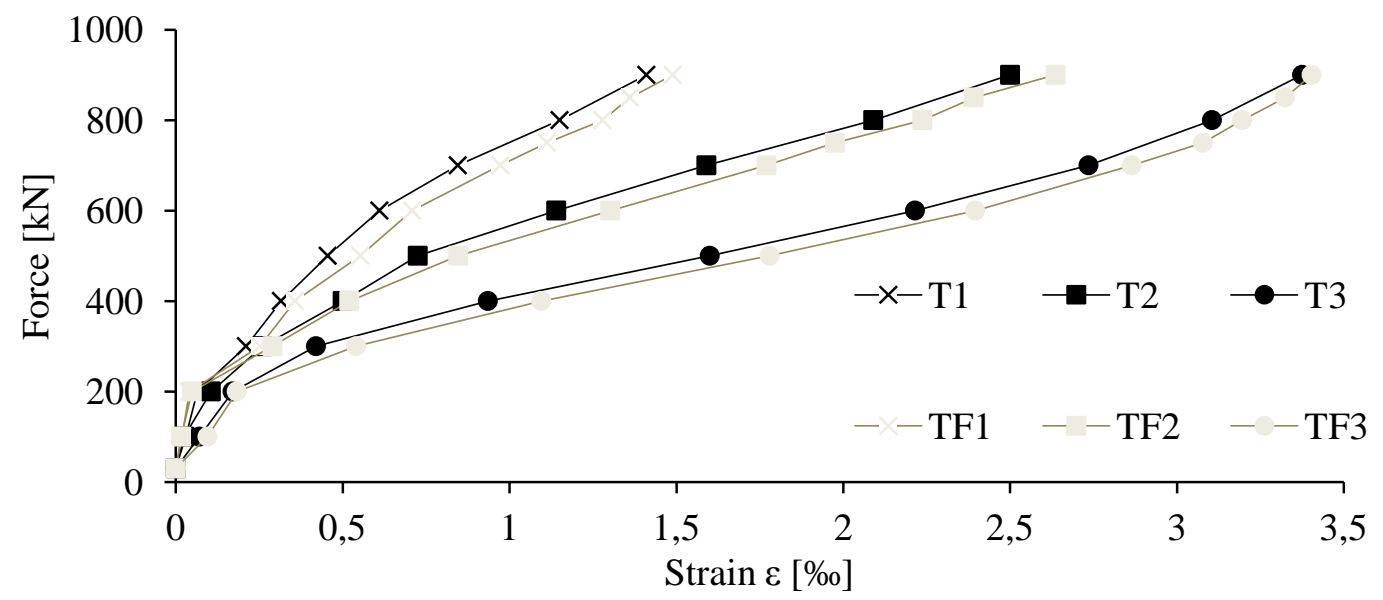

Fig. 4: Comparison of strains obtained by photogrammetric (TF) and deformeter (T) measurement in tangential direction.

The XY plane was defined parallel to the object's surface; however, the rotation of this plane around the $\mathrm{Z}$ axis was irrelevant, because the aim was to compute only the relative changes in lengths observed in the $3 \mathrm{D}$ coordinate system and not the changes in the specific directions of the $\mathrm{X}$ or $\mathrm{Y}$ axes. The $+\mathrm{Z}$ axis was pointing upward, so it was possible to compare the changes in the photogrammetric $\mathrm{Z}$ coordinates and the deflection in the middle of the specimen measured by LVDT (Fig. 5). 


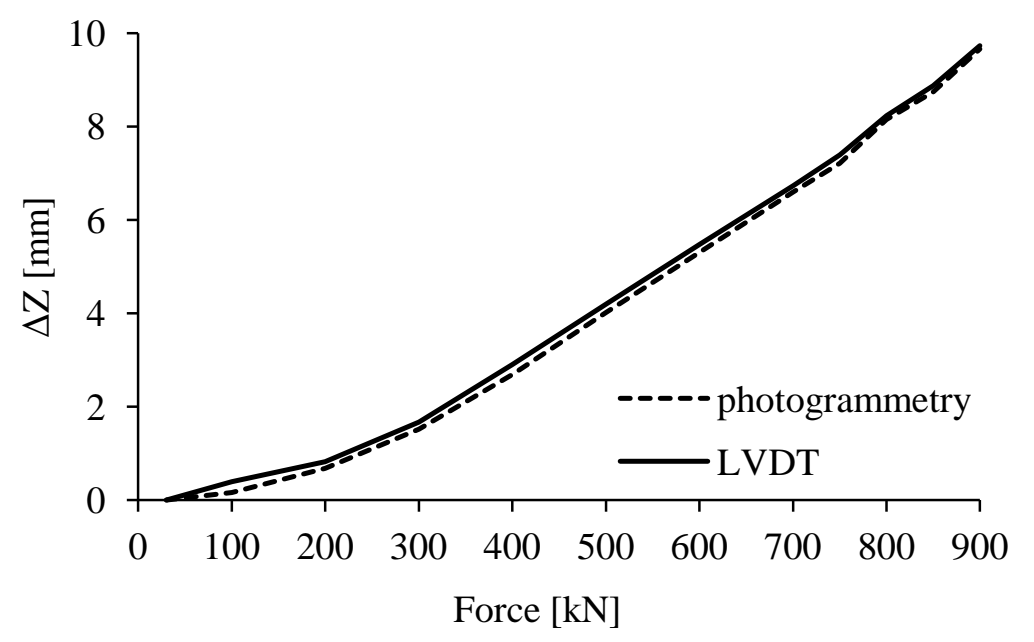

Fig. 5: Comparison of the deflection in the center of the specimen determined by photogrammetry and by the LVDT.

If we take into account the fact that the differences between the comparable strains reached an average value of $0.1 \%$, we deal with a value change of $0.02 \mathrm{~mm}$ for a $200 \mathrm{~mm}$ length. Such a degree of precision is sufficient for the needs of deformation measurement during load tests of construction elements.

The use of photogrammetry for this purpose also opens the question of safety during the loading - in contrary to the direct contact measurement using a deformeter.

\section{Conclusions}

The results from the actual measurements demonstrate that multi-image convergent photogrammetry is an effective, accurate and suitable method for displacement measurements during load tests of construction elements, especially if optimal camera configuration is provided. It enables contactless control not only of the points on the object tested but also on the load-test construction around it. Thanks to this distribution of points, it can produce a complex image of the deformations of the object observed and, after a deep analysis, it can help adjust the loading structure by correcting any unreliable elements.

\section{Acknowledgement}

This work was supported by the Slovak Research and Development Agency under the contract No. APVV-15-0658 and Scientific Grant Agency of the Ministry of Education, science, research and sport of the Slovak Republic and the Slovak Academy of Sciences No 1/0810/16.

This article is the result of the implementation of the KEGA project No. 037STU-4/2016 "Modernization and Development of Technological Skills in teaching Surveying and Photogrammetry”.

\section{References}

Chounta, I., Ioannidis, C. (2012). High accuracy deformation monitoring of a concrete beam using automatic photogrammetric techniques. FIG Working Week "Knowing to manage the territory, protect the environment", Rome, Italy, 6-10 May, 2012.

Detchev, I., Habid, A., El-Badry, M. (2011) Case study of beam deformation monitoring using conventional close range photogrammetry. ASPRS annual conference, Milwaukee, Wisconsin, May1-5, 2011.

Lee, T. K., Al-Mahaidi, R. (2008) An experimental investigation on shear behaviour of RC T-beams strengthened with CFRP with photogrammetry. Composite Structures 82(2), pp. 185-193.

Luhmann, T., Robson, S., Kyle, S., Harley, I. (2006) Close-Range Photogrammetry. Whittles Publishing, Dunbeath, Scotland, UK. pp. 374 - 376. ISBN 1-870325-50-8.

Luhmann, T. (2010) Close range photogrammetry for industrial applications. ISPRS Journal of Photogrammetry and Remote Sensing, 65 (2010), pp. 558-569. doi: 10.1016/j.isprsjprs.2010.06.003.

Valença, J., Júlio, E. and Araújo, H. (2012) Application of photogrammetry to structural assessment. Experimental Techniques, 36(5), 71-81. 